\title{
A Unified Satellite Taxonomy Proposal Based on Mass and Size
}

\author{
Rui C. Botelho A. S. ${ }^{*}$, Ademir L. Xavier Jr. ${ }^{2}$ \\ ${ }^{1}$ Wyden University Center (UniRuy), Salvador, Brazil \\ ${ }^{2}$ Brazilian Space Agency (AEB), Brasília, Brazil \\ Email: *ruicbs@gmail.com
}

How to cite this paper: Botelho A. S., R.C. and Xavier Jr., A.L. (2019) A Unified Satellite Taxonomy Proposal Based on Mass and Size. Advances in Aerospace Science and Technology, 4, 57-73.

https://doi.org/10.4236/aast.2019.44005

Received: September 24, 2019

Accepted: October 26, 2019

Published: October 29, 2019

Copyright (c) 2019 by author(s) and Scientific Research Publishing Inc. This work is licensed under the Creative Commons Attribution International License (CC BY 4.0).

http://creativecommons.org/licenses/by/4.0/

\section{cc) (i) Open Access}

\begin{abstract}
The classification of spacecraft by mass is one of the main metrics to define the size of launch vehicles and the costs of launching satellites into orbit. The existence of many classifications (based on size categories and mass range values) makes inaccurate their common global characterization. This paper presents a review of the main satellite classifications schemes and a brief discussion about the current trends in the launcher market as an input to the satellite classification. Based on mass and size ranges and considering previous schemes and launching capabilities, a new classification arrangement is then proposed. According to the new scheme, satellites are grouped into 10 categories following specific rules depending on mass and size. In addition to unifying previous definitions of categories for small satellites, our new spacecraft taxonomy has the advantage of creating classes for very large space devices, such as space stations and potential interplanetary exploration missions.
\end{abstract}

\section{Keywords}

Classification, Satellite, Spacecraft, Payload, Taxonomy

\section{Introduction}

From 1950 to 1990, the increased number of spacecraft launches was accompanied by the continuous growth in size, mass, and cost of satellites, in parallel with the admittance of an increasing variety of payloads in many space missions [1]. The trend was observed until the year 2000 and was characterized by the launch and operation of large satellites as true space laboratories serving a variety of applications. With a mass of nearly $8200 \mathrm{~kg}$, Envisat is a good example of this era [2]. 
With advances in microelectronics in the 80s and extensive miniaturization of integrated circuits, a cost reduction was observed in many space dedicated computer systems, together with an increase in their complexity. Starting in the 1990s [1] [3] [4], such technological changes set up both a new scenario and the coexistence of large and traditional spacecraft with newer and much smaller (and efficient) satellites. The dichotomy implied the need for separating the two trends, old and new, in order to provide a proper classification of each of its constituting parts. Mass and size are the main parameters which impact the definition of requirements such as mission cost, orbit type, and many others, but mainly launch lifting power.

Having acquired the status of a systematic classification process, taxonomy is widely employed in a variety of sciences: biology [5], astronomy [6] [7] [8], pedology, among others. The multiplicity and variety of phenomena give rise to taxonomical classes. In biology, taxonomy provided a systematic classification of its objects of study, something that would reveal an even deeper order of causes later, such as natural evolution [9]. Similarly, the progression of specific technology devices can be described in taxonomical terms, which also implies an underlying order as a result of technological advancement [10] [11] and project management. The same can be said about space developments, and, in particular, of satellites [1] [12]. However, despite the existence of many satellite classifications and categories-which we call here satellite taxonomy-convergence is still missing or, at least, an agreement among seemingly equivalent terminologies depending on the country, manufacturer or research institution responsible for the classification scheme [3]. In fact, more than ever, a recommendation separated from the guidance of any particular or private drives should be sought in order to provide a better way of classifying future developments.

This paper presents a unified taxonomy proposal of 10 classes of satellites, grouped by mass and size, in the order of thousands of tons to the gram fraction [13]. In terms of size, the classes defined by mass were divided into 9 categories of sizes, ranging from ultra-very large to ultra-very small. In addition to unifying the definitions of categories for small satellites, this work has the advantage of creating classes for very large mass space devices, such as space stations and potential interplanetary missions.

Toward this aim, this work is organized as follows: Section 2 is a review of past classification schemes, including those dedicated to recent nanosatellites, a necessary step before any new classification recommendation; in Section 3 a review of present and future launch vehicles in terms of their lifting power is made as an orientation for new classification heuristics involving mainly large payloads (such as space stations). Finally, Section 4 presents the new classification arrangement with the final conclusions in Section 5.

\section{Review of Some Satellite Classifications Schemes}

This section reviews some of the existing classification types in the literature as an introduction to satellite classification. From this initial review, it is possible to 
identify similarities and differences as an initial base to establish a new proposal.

\subsection{Classification Based on Satellite Mass}

Some attempts to classify satellites began in the 1990s using mass as the only parameter. Martin Sweeting coined the first satellite classes in 1991 (Table 1). The scheme did not consider other characteristics such as spacecraft complexity, function or application, but was a recommendation much more related to launch cost for which mass is the main parameter to be considered. In summary, Sweeting's first proposal represented mainly the view of the launching service.

With the increasing number and variety of applications, service requirements and system miniaturization [14] refined the previous classification (Table 2), replacing small class for medium and dividing nanosatellite class into three groups: nanosatellite $(1-10 \mathrm{~kg})$, pico-satellite $(0.1-1 \mathrm{~kg})$ and femto-satellite $(0.001-0.1$ $\mathrm{kg}$ or $1-100 \mathrm{~g}$ ). Kramer and Cracknell [1] reviewed the Konecny [14] classification, merging the classes of medium-satellites $(500-1000 \mathrm{~kg})$ and mini-satellites $(100-500 \mathrm{~kg})$ in the range of $100-1000 \mathrm{~kg}$ (Table 3). Many authors and institutions ([15], apud [4]) have adopted an upper limit of $1000 \mathrm{~kg}$ for the masses of mini-satellites. The same limit was assumed at UNISPACE III [16] where the cost of developing and manufacturing such satellites was estimated to be in the range \$5 - 20 million for mini-satellites, \$2 - 5 million for microsatellites and less than $\$ 1$ million for nanosatellites [4]. Despite being an accepted reference separating the classes in power of 10 , the classification of Table 3 is not practical neither well-adjusted to cost (including launch cost), because it blends, in the same class, satellites in the mass range $100-1000 \mathrm{~kg}$. In principle, such mass range would contain devices of quite different cost and complexity, given the history of space missions of the last decades as presented by [4].

The standardization of class names may also depend on the entity or agency in charge of running the space mission. According to Table 4 listed below, ESA (the European Space Agency) classifies satellites in the following types: small satellites with mass between $350-700 \mathrm{~kg}$, mini-satellites with $80-350 \mathrm{~kg}$ and micro-satellites with 50 - $80 \mathrm{~kg}$ (Table 4). On the other hand, EADS/Astrium specified mass ranges larger than the values of other schemes (Table 5) for some classes (e.g., mini-satellite), while it added subcategories for mini-satellites ("miniXL", $1000-1300 \mathrm{~kg}$, and "mini”, $400-700 \mathrm{~kg}$ ). In addition, EADS/Astrium defined a

Table 1. A first satellite classification by mass scheme by Sweeting [12] (apud [1]).

\begin{tabular}{cc}
\hline Satellite class & Mass $(\mathrm{kg})$ \\
\hline Large & $>1000$ \\
Small & $500-1000$ \\
Mini & $100-500$ \\
Micro & $10-100$ \\
Nano & $<10$ \\
\hline
\end{tabular}


Table 2. Satellite classification by Konecny [14].

\begin{tabular}{cc}
\hline Satellite class & Mass $(\mathrm{kg})$ \\
\hline Large & $>1000$ \\
Medium & $500-1000$ \\
Mini & $100-500$ \\
Micro & $10-100$ \\
Nano & $1-10$ \\
Pico & $0.1-1$ \\
Femto & $<0.1$ \\
\hline
\end{tabular}

Table 3. Satellite classification in powers of 10 as adapted from [1].

\begin{tabular}{cc}
\hline Satellite class & Mass (kg) \\
\hline Large (observatories, etc.) & $>1000$ \\
Mini Smallsats (or light satellites) & $100-1000$ \\
Micro & $10-100$ \\
Nano & $1-10$ \\
Pico & $0.1-1$ \\
Femto Satellite-on-a-chip & $0.01-0.1$ \\
\hline
\end{tabular}

Table 4. ESA classes [4].

\begin{tabular}{cc}
\hline Satellite class & Mass $(\mathrm{kg})$ \\
\hline Small & $350-700$ \\
Mini & $80-350$ \\
Micro & $50-80$ \\
\hline
\end{tabular}

Table 5. EADS/Astrium classes [4].

\begin{tabular}{cc}
\hline Satellite class & Mass $(\mathrm{kg})$ \\
\hline Mini XL & $1000-1300$ \\
Mini & $400-700$ \\
Micro & $100-200$ \\
\hline
\end{tabular}

different mass range for micro-satellites, 100 - $200 \mathrm{~kg}$. Oddly enough, two ranges were not covered by EADS/Astrium's scheme, namely $300-400 \mathrm{~kg}$ and 700 $1000 \mathrm{~kg}$ [4].

ESA and EADS/Astrium classifications do not explicitly define classes for medium and/or large satellites, which is implicit by the fact that the top limits of their classification scheme are, respectively, $700 \mathrm{~kg}$ and $1300 \mathrm{~kg}$. Hence, for standardization purposes, large systems must be properly defined. The same reasoning may be found in other studies, where only mass thresholds among classes were changed. NASA scheme (of 2015) defines small satellites (Table 6, 
i.e., "SmallSats") as space devices with mass below $180 \mathrm{~kg}$ [17] and "maximum size equivalent to a refrigerator". NASA's classification also not explicitly defines values for medium or large satellites (biggest than $180 \mathrm{~kg}$ ).

Application using small satellites in commercial and scientific space missions is relatively new in Russia [3]. The Russian classification follows mass ranges as given by Table 7. According to this scheme, there is no consensus for the limit values between mini and micro-satellite classes. Also, unlike NASA's definition, a femto-satellite class is missing. Thus, a femto-satellite group could be added as a possible extension of this classification, considering the lower limit value for pico satellites.

Wekerle et al. [18] argued that small satellites should be classified as spacecraft with mass smaller than or equal to $500 \mathrm{~kg}$ (Table 8). As seen in other classifications, a class for the "femto" type is not defined in [18] as well. The radio communication sector of the International Telecommunication Union (ITU) [19] defined categories for mini-satellites, microsatellites, nanosatellites, and pico-satellites similar to the classification presented by [18]. Unlike previous recommendations,

Table 6. NASA satellite classes [3].

\begin{tabular}{cc}
\hline Satellite class & Mass $(\mathrm{kg})$ \\
\hline Mini & $100-180$ \\
Micro & $10-100$ \\
Nano & $1-10$ \\
Pico & $0.01-1$ \\
Femto & $0.001-0.01$ \\
\hline
\end{tabular}

Table 7. ROSCOSMOS classes (adapted from [3]) with the addition of a class dedicated to femto-satellites.

\begin{tabular}{cc}
\hline Satellite class & Mass $(\mathrm{kg})$ \\
\hline Small & $500-1000$ \\
Mini & $100-500 \mathrm{~kg}$ or $150-500$ \\
Micro & $10-100 \mathrm{~kg}$ or $10-150$ \\
Nano & $1-10$ \\
Pico & $0.01-1$ \\
\hline
\end{tabular}

Table 8. Wekerle et al. [18] classification scheme, adapted.

\begin{tabular}{cc}
\hline Satellite class & Mass $(\mathrm{kg})$ \\
\hline Large/Satellite & $>500$ \\
Mini & $101-500$ \\
Micro & $11-100$ \\
Nano & $1-10$ \\
Pico & $<1$ \\
\hline
\end{tabular}


however, a class dedicated to femto-satellites is present in ITU scheme as shown in Table 9.

The FAA (Federal Aviation Administration) presented a classification for the purpose of defining launch requirements [20], Table 10. However, from 2016 onwards, several FAA yearbooks (2016, 2017 and 2018) have added progressively new categories [21] [22] [23] (Table 10) which are closer to the previous classifications presented here than the original one by FAA, as shown by Table 11, although some differences may be observed regarding the pattern of ranges used [1].

\subsection{Classification of Nanosatellites and Cubesats}

Our review must include the schemes of the so-called "small satellites", where

Table 9. ITU (2014) classification with emphasis to small satellites, adapted from [19].

\begin{tabular}{cc}
\hline Satellite class & Mass $(\mathrm{kg})$ \\
\hline Mini & $100-500$ \\
Micro & $10-100$ \\
Nano & $1-10$ \\
Pico & $0.1-1$ \\
Femto & $\leq 0.1$ \\
\hline
\end{tabular}

Table 10. FAA (2015) satellite classes, adapted from [20].

\begin{tabular}{cc}
\hline Satellite class & Mass $(\mathrm{kg})$ \\
\hline Extra heavy & $>5400$ \\
Heavy & $4200-5400$ \\
Intermediate & $2500-4200$ \\
Medium & $<2500$ \\
\hline
\end{tabular}

Table 11. FAA (2018) new classes for payloads, adapted from [23].

\begin{tabular}{cc}
\hline Satellite class & Mass $(\mathrm{kg})$ \\
\hline Extra heavy & $>7100$ \\
Heavy & $5401-7000$ \\
Large & $4201-5400$ \\
Intermediate & $2501-4200$ \\
Medium & $1201-2500$ \\
Small & $601-1200$ \\
Mini & $201-600$ \\
Micro & $11-200$ \\
Nano & $1.1-10$ \\
Pico & $0.09-1$ \\
Femto & $0.01-0.1$ \\
\hline
\end{tabular}


"small" refers to nanosatellite devices of arbitrary shape and function, but with a well-defined maximum mass limit (in general close to $10 \mathrm{~kg}$ ). As it will be seen, no consensus exists with regard to the way smallsats should be classified but the same mass rule is generally used. Nanosatellites emerged in the late 90s [24] [25] initially as dedicated missions for system engineering students. Soon, however, their application involved relevant missions of scientific and commercial value [1]. With their emergence, a new classification also arose after the quantization of dimension or volume which distinguishes cubesats from general nanosatellites as a standard. About $50 \%$ of satellites with a mass lower than $10 \mathrm{~kg}$ are based on the same cubic architecture of $1 \mathrm{U}(10 \times 10 \times 10 \mathrm{~cm})$ extendible to $12 \mathrm{U}$ (Table 12). Many of the current missions are still heavily educational and are built on predefined platforms based on COTS (Commercial Off the Shelf), which have contributed to a new commercial trend in space activities [1] [4] [18].

Theoretically, the cubesat standard does not constraint the mass. The modular structure only defines a subset of the nanosatellite class. Cubesats with larger masses $(>10 \mathrm{~kg}$ ) are possible as indicated in Table 12 for a $12 \mathrm{U}$ arrangement with $15 \mathrm{~kg}$, but the final system should be more properly classified as a microsatellite (10 - $100 \mathrm{~kg})$. Depending on the material density used to build a $12 \mathrm{U}$ cubesat, however, its mass may fall within the $10 \mathrm{~kg}$ threshold. Thus, mass defines a rule for the final classification in spite of shape or size: a heavy cubesat should be classified in fact as a microsatellite.

\subsection{Discussion about the Reviewed Classes}

The use of mass classes separated by powers of 10 facilitates the definition of types with clear lower and upper bounds. In addition, the common practice is to dissociate size from any class definition because a small satellite may belong to several distinct classes at the same time depending on its mass. For satellites with less than $1000 \mathrm{~kg}$, well-defined classes are more common while the opposite does not happen with large satellites for which no specific categories exist.

From what has been seen so far, the current nomenclature of mass and size does not make any reference to terms such "heavy" and "light" as qualifiers of satellite classes, notwithstanding the strong mass-oriented approach. Here we emphasize a decomposition of the attributes of weight, size and class names in order to avoid any direct association of these separate dimensions of satellite

Table 12. Type, volume, mass and description of some cubesats as a subset of nanosatellites, adapted from [4].

\begin{tabular}{cccl}
\hline Type & Volume $(\mathrm{cm} \times \mathrm{cm} \times \mathrm{cm})$ & Mass $(\mathrm{Kg})$ & Description \\
\hline $12 \mathrm{U}$ & $\sim 10 \times 40 \times 30$ & $\sim 15$ & Micro-satellite \\
$6 \mathrm{U}$ & $\sim 10 \times 20 \times 30$ & $\sim 10$ & Nanosatellite \\
$3 \mathrm{U}$ & $\sim 10 \times 10 \times 30$ & 3.99 & Nanosatellite \\
$2 \mathrm{U}$ & $10 \times 10 \times 20$ & 2 & Nanosatellite \\
$1 \mathrm{U}$ & $\sim 10 \times 10 \times 10$ & 1.33 & Nanosatellite \\
\hline
\end{tabular}


description with a unique class characterization. From what has been seen so far, it is possible to summarize the classification of small satellites into preliminary categories as shown in Table 13. This table follows almost completely the class and mass "philosophy" established by [1], with ranges limits defined in powers of 10 (according to Table 3), adding a column for size as an additional descriptive attribute. Also, using the contribution of other classifications, small satellites were defined with mass range $1-500 \mathrm{~kg}$, and separated into additional subcategories using the prefixes mini (500 - $1000 \mathrm{~kg}$ ), micro and nano. Below $1 \mathrm{~kg}$, "pico" and "femto" classes had not their mass values changed but were further subdivided in accordance to size attributes such as "very small" and "ultrasmall".

\section{Relating Satellite Mass with Launch Vehicle Lift Capacity}

Launch requirements should be considered from the very beginning of the mission definition, and are generated from an initial assessment of the mass range and size of the satellite to be launched [20].

While satellites underwent a strong size reduction with miniaturization, launchers followed the opposite path of a progressive increase in lift power motivated primarily by the need of reducing the average cost per kilogram transported into space using the concept of multiple satellite insertions on a single launch. The cost reduction was also partially founded on the resurgence of past initiatives of exploring the moon, Mars, and asteroid mining now an activity counting on the participation of private companies. Such a trend of increasing launching offer is expected to continue in the short to middle terms with operational costs following the reverse path [26].

Just as in the case of satellite classification, several classes were defined for launch vehicles in terms of their payload lift capacity. FAA [23] presented, for example, a very succinct classification of launch vehicles with two categories only (Table 14), and for an insertion altitude of $185 \mathrm{~km}$ at $28.5^{\circ}$ of inclination. Essentially, FAA scheme distinguishes launch vehicles as a function of a threshold of $2268 \mathrm{~kg}$ (5000 lb): medium, heavy and, small.

Table 13. Summary table containing name, mass and size as attributes based on the reviewed classifications.

\begin{tabular}{ccc}
\hline Class & Mass $(\mathrm{kg})$ & Size \\
\hline \multirow{2}{*}{ Satellite } & $>10,000$ & Very large \\
& {$[3000-10,000[$} & Large \\
& {$[1000-3000[$} & Medium \\
Mini & {$[500-1000[$} & \\
Micro & {$[100-500[$} & Small \\
Nano & {$[10-100[$} & \\
Pico & {$[1-10[$} & Very small \\
Femto & {$[0.1-1[$} & Ultra small \\
\hline
\end{tabular}


NASA (2010) classification document [27] distinguishes launch vehicles in 4 categories as shown in Table 15. This classification scheme further subdivides the Heavy-Medium category in 3 classes: Medium, Heavy and Super Heavy. The class small is similar to the FAA definition [23], but, being older, it does not specify any smaller classes to encompass vehicles dedicated to launching small loads, the so-called micro-launchers.

Werkerle et al. [18] presented a classification similar to NASA's (2010) [27] regarding small and medium class vehicles (Table 16). However, despite the presence of a special class for microlaunchers $(<500 \mathrm{~kg})$, a special class lacks for super heavy vehicles $(>50,000 \mathrm{~kg})$.

In order to illustrate how these classifications could be applied, a list containing several operational launchers is shown in Table 17 organized in lifting power. Table 18 features another list, organized in the same way, but for estimated lift masses of current planned launchers. In both cases, an insertion orbit similar to the one defined by FAA was used as reference [23].

The characteristic payload mass ranges as shown in these tables are incompatible with current satellite classifications assuming a single payload insertion. Despite the fact that many launchers are able to putseveral satellites in orbit on a single launch-the main drive for launch cost reduction-there remains the possibility of lifting masses much larger than the current values defined as the upper threshold of many schemes. Therefore, the classification may be modified to accommodate special categories of heavy-lift vehicles dedicated to larger payloads.

Table 14. FAA (2018) classes of launchers [23].

\begin{tabular}{cc}
\hline LV class & Payload mass $(\mathrm{kg})$ \\
\hline Medium-Heavy & $>2268$ \\
Small & $\leq 2268$ \\
\hline
\end{tabular}

Table 15. NASA (2010) classes of launchers, adapted [27].

\begin{tabular}{cc}
\hline LV class & Payload mass $(\mathrm{kg})$ \\
\hline Super Heavy & $>50,000$ \\
Heavy & ] $20,000-50,000]$ \\
Medium & ] $2000-20,000]$ \\
Small & $\leq 2000$ \\
\hline
\end{tabular}

Table 16. Wekerle et al. classes for launchers, adapted from [18].

\begin{tabular}{cc}
\hline LV class & Payload mass $(\mathrm{kg})$ \\
\hline Heavy & $>20,000$ \\
Medium & $2001-20,000$ \\
Small & $501-2000$ \\
Micro & $\leq 500$ \\
\hline
\end{tabular}


Table 17. Examples of active launch vehicles, their payload capacities up to $\mathrm{LEO}^{1}$ and the respective ratings according to Wekerle et al. (2017) [18] and NASA (2010) [27], sorted by payload capacity.

\begin{tabular}{|c|c|c|c|c|}
\hline \multirow{2}{*}{ LV } & \multirow{2}{*}{ Country/Manufacturer } & \multirow{2}{*}{$\begin{array}{l}\text { Injection mass } \\
\text { in LEO }(\mathrm{kg})\end{array}$} & \multicolumn{2}{|c|}{ Classification } \\
\hline & & & Wekerle et al. & NASA \\
\hline Electron & New Zealand/Rocket Labs & 225 & Micro & Small \\
\hline Epsilon & Japan/IHI & 1200 & Small & Small \\
\hline Strela & Russia/Khrunichev & 1400 & Small & Small \\
\hline Minotaur-C(Taurus) & USA/Orbital & 1450 & Small & Small \\
\hline Minotaur IV & USA/Orbital & 1735 & Small & Small \\
\hline$P S L V-X L$ & India/ISRO & 3800 & Medium & Medium \\
\hline Long March $2 D$ & China/SAST & 4000 & Medium & Medium \\
\hline Long March $4 C$ & China/SAST & 4200 & Medium & Medium \\
\hline GSLV Mk II & India/ISRO & 5000 & Medium & Medium \\
\hline Antares 230 & USA/Orbital ATK & 6500 & Medium & Medium \\
\hline Zenit-3SL & Ukraine/RKK Energia & 7000 & Medium & Medium \\
\hline Soyuz-2.1b (Baikonour) & Russia/TsSKB-Progress & 8200 & Medium & Medium \\
\hline Long March $2 F$ & China/CALT/ & 8600 & Medium & Medium \\
\hline Soyuz ST-B (Kourou) & Russia/TsSKB-Progress & 9000 & Medium & Medium \\
\hline GSLV Mk III & India/ISRO & 10,000 & Medium & Medium \\
\hline H-IIA 202 & Japan/Mitsubishi & 10,000 & Medium & Medium \\
\hline Long March $3 B / E$ & China/CALT & 11,500 & Medium & Medium \\
\hline Atlas V 521 & USA/ULA & 13,300 & Medium & Medium \\
\hline Long March 7 & China/CALT & 13,500 & Medium & Medium \\
\hline Delta IV M+ $(5,4)$ & USA/ULA & 14,140 & Medium & Medium \\
\hline$H-I I B$ & Japan/Mitsubishi & 16,500 & Medium & Medium \\
\hline Atlas V552 & USA/ULA & 20,520 & Heavy & Heavy \\
\hline Ariane 5 ES & Europe/EADS Astrium & 21,000 & Heavy & Heavy \\
\hline Falcon 9 Full Thrust & USA/SpaceX & 22,800 & Heavy & Heavy \\
\hline Proton-M/M+ & Russia/Khrunichev & 23,000 & Heavy & Heavy \\
\hline Long March 5 & China/CALT & 25,000 & Heavy & Heavy \\
\hline Delta IV Heavy & USA/ULA & 28,790 & Heavy & Heavy \\
\hline Falcon Heavy & USA/SpaceX & 63,800 & Heavy & Super heavy \\
\hline
\end{tabular}

Table 18. Examples of several launchers projects, their estimated payload capacity up to LEO1 and the respective ratings according to Wekerle et al. (2017) [18] and NASA (2010) [27], sorted by payload capacity.

\begin{tabular}{ccccc}
\hline \multirow{2}{*}{ LV } & Country/Manufacturer & \multirow{2}{*}{$\begin{array}{c}\text { Injection mass } \\
\text { in LEO }(\mathrm{kg})\end{array}$} & \multicolumn{2}{c}{ Classifications } \\
\cline { 4 - 5 } & & Wekerle et al. & NASA \\
\hline Ariane Q@TS & Europe/ArianeGroup & 100 & Micro & Small \\
Orbex Prime & Spain-UK/Deimos-Orbex & 150 & Micro & Small \\
$V L M-1$ & IAE-Avibrás/Brazil & 150 & Micro & Small \\
\hline
\end{tabular}

${ }^{1}$ Data collected and compiled from several sources. 


\begin{tabular}{|c|c|c|c|c|}
\hline Continued & & & & \\
\hline Arion 2 & PLD Space/Spain & 300 & Micro & Small \\
\hline$K S L V-2$ & S. Korea/KARI & 1500 & Small & Small \\
\hline Naga-L & China/CALT & 1590 & Small & Small \\
\hline Vega $E$ & Europe/ESA/ASI & 2000 & Small & Small \\
\hline Vega $C$ & Europe/ESA/ASI & 2300 & Medium & Medium \\
\hline Angara 1.2 & Russia/Khrunichev & 3800 & Medium & Medium \\
\hline Ariane 6 A62 & Europe/ArianeGroup & 10,350 & Medium & Medium \\
\hline Proton Light & Russia/Khrunichev & 16,000 & Medium & Medium \\
\hline Ariane 6 A64 & Europe/ArianeGroup & 21,650 & Heavy & Heavy \\
\hline Proton Medium & Russia/Khrunichev & 23,000 & Heavy & Heavy \\
\hline Vulcan 561 with ACES & USA/ULA & 35,000 & Heavy & Heavy \\
\hline New Glenn (2 Stages) & USA/Blue Origin & 45,000 & Heavy & Heavy \\
\hline SLS Block 1 & $\begin{array}{c}\text { USA/NASA/Boeing (core)/ } \\
\text { Orbital ATK (SRBs) }\end{array}$ & 95,000 & Heavy & Super heavy \\
\hline SLS Block $1 B$ with EUS & $\begin{array}{l}\text { USA/NASA/Boeing (core)/ } \\
\text { Orbital ATK (SRBs) }\end{array}$ & 105,000 & Heavy & Super heavy \\
\hline SLS Block 2 with EUS & USA/NASA/Boeing & 130,000 & Heavy & Super heavy \\
\hline Long March 9 & China/CALT & 140,000 & Heavy & Super heavy \\
\hline Big Falcon Rocket (BFR) & USA/SpaceX & 150,000 & Heavy & Super heavy \\
\hline $\begin{array}{c}\text { Interplanetary Transport } \\
\text { System }\end{array}$ & USA/SpaceX/NASA & $300,000 / 550,000$ & Heavy & Super heavy \\
\hline
\end{tabular}

\section{Unified Taxonomy Proposal for Satellites in Accordance to Mass and Size}

The proposal presented here organizes and standardizes satellite classes in powers of 10 as originally suggested by [1] (Table 19) and further subdivides satellites according to their size, making the most of the past schemes as reviewed in the previous section. However, new subclasses (types) are added in order to specify supplementary categories of larger systems that are expected as innovation in future exploratory missions. Following the suggestive tradition of using Latin prefixes to name each class, most of the added class names were also chosen from Latin prefixes-which are largely used in SI units. However, the proposed names are only an extension of the previous practice, no relation exists between them and the mass ranges values. The class numbering follows an exponent of base 10 of the upper value in kilograms at each assigned interval (Table 19).

For each proposed classes, the following comments apply:

- Class 7-“Mega": created to accommodate a spacecraft with mass over 1000 tons to be used in interplanetary missions, but which are still unfeasible in the short term. This special class was added as a threshold to the upper classes. Possible subdivisions may be added later. In principle, considering the present launch lift powers, a spacecraft of this type would be assembled in space before reaching the final orbit. Megasats are characterized by the size UVL (Ultra Very Large). 
Table 19. Proposed classes for satellite and other spacecraft using mass and size as mainattributes of identification.

\begin{tabular}{|c|c|c|c|c|c|}
\hline \multicolumn{3}{|r|}{ Class } & \multicolumn{2}{|c|}{ Subclass } & \multirow[t]{2}{*}{ Size } \\
\hline \# & Name & Mass (kg) & Type & Mass (kg) & \\
\hline 7 & Mega & $>1,000,000$ & - & - & Ultra very large \\
\hline \multirow{3}{*}{6} & \multirow{3}{*}{ Hecto } & \multirow{3}{*}{$100,000-1,000,000[$} & Heavy & {$[600,000-1,000,000[$} & \multirow{3}{*}{ Ultra large } \\
\hline & & & Intermediary & {$[300,000-600,000[$} & \\
\hline & & & Light & {$[100,000-300,000[$} & \\
\hline \multirow{3}{*}{5} & \multirow{3}{*}{ Deca } & \multirow{3}{*}{$10,000-100,000[$} & Heavy & {$[60,000-100,000[$} & \multirow{3}{*}{ Very large } \\
\hline & & & Intermediary & {$[30,000-60,000[$} & \\
\hline & & & Light & {$[10,000-30,000[$} & \\
\hline \multirow{4}{*}{4} & \multirow{4}{*}{ Protypos } & \multirow{4}{*}{$1,000-10,000[$} & Heavy & {$[6,000-10,000[$} & \multirow{2}{*}{ Large } \\
\hline & & & Intermediary & {$[3000-6000[$} & \\
\hline & & & Light & {$[1000-3000[$} & \multirow{2}{*}{ Medium } \\
\hline & & & Heavy & {$[500-1000[$} & \\
\hline \multirow[t]{2}{*}{3} & \multirow[t]{2}{*}{ Mini } & \multirow[t]{2}{*}{$100-1000[$} & Intermediary & {$[180-500[$} & \multirow{11}{*}{ Small } \\
\hline & & & Light & {$[100-180[$} & \\
\hline \multirow{3}{*}{2} & \multirow{3}{*}{ Micro } & \multirow{3}{*}{$10-100[$} & Heavy & {$[60-100[$} & \\
\hline & & & Intermediary & {$[25-60[$} & \\
\hline & & & Light & {$[10-25[$} & \\
\hline \multirow{6}{*}{1} & \multirow{6}{*}{ Nano } & \multirow{6}{*}{$1-10[$} & & {$[8-10[$} & \\
\hline & & & & {$[6-7.99[$} & \\
\hline & & & Cubesat & {$[3-3.99[$} & \\
\hline & & & & {$[2-2.66[$} & \\
\hline & & & & {$[1-1.33[$} & \\
\hline & & & Others shapes & {$[1-10[$} & \\
\hline 0 & Pico & {$[0.1-1[$} & - & - & Very small \\
\hline-1 & Femto & {$[0.01-0.1[$} & - & - & Ultra small \\
\hline-2 & Gram & $<0.01$ & - & - & Ultra very small \\
\hline
\end{tabular}

- Class 6-"Hecto": with masses in the range 100 - 1000 tons, the class is split in three subclasses: heavy, intermediate and light. As an example, ISS is a hectosat with mass $420,000 \mathrm{~kg}$ of the intermediate type. Hectosats are characterized by size as UL (Ultra Large).

- Class 5- "Deca": encompassing spacecraft in the range 10 - 100 tons with subclasses heavy, intermediate and light. Hubble space telescope and many military US satellites (USA-182 and USA-245) are examples of light decasats. Decasats are characterized by size as VL (Very Large).

- Class 4-"Protypo": encompassing satellites in the range 1 - 10 tons and dis- 
tributed as heavy, intermediate and light. This class name is an abbreviation

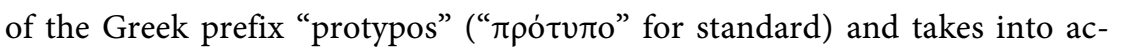
count the average mass of many active satellites $(\sim 1600 \mathrm{~kg})$. It also contemplates the average mass of many telecommunication satellites (including geostationary) which represents about $60 \%$ of spacecraft in orbit with masses in the range 3500 - $5200 \mathrm{~kg}$. Protyposats are classified as L (Large) provided their masses are above $3000 \mathrm{~kg}$ (with types intermediate and heavy). Below this value, they are associated with the size $M$ (Medium). Examples of light protyposats are SGDC-1, CBERS-4A, while GOES-R and INMARSAT IV-A F4 belong to the intermediate and heavy types.

- Class 3- "Mini": for satellites in the mass range $100-1000 \mathrm{~kg}$, distinguished by the types heavy, intermediate and light. Minisats are characterized by size as medium and small if their masses are above or below $500 \mathrm{~kg}$, respectively. Present examples of minisats are SDC (1 and 2) and NovaSAR-1, which may be classified as light and intermediate satellites, respectively. Both are however smallsats in terms of size. Zhangheng-1 is a heavy minisat of medium size.

- Class 2- "Micro": defining satellites with mass in the range $10-100 \mathrm{~kg}$ divided in heavy, intermediate and light types. All spacecraft of this category are classified as smallsats in terms of size. The class also considers cubesats of volume $12 \mathrm{U}$ or larger, provided the mass is over $10 \mathrm{~kg}$. Examples of microsats are Saudicomsat $1 / 2 / 3 / 4 / 5 / 6 / 7(11-13 \mathrm{~kg})$ and the Indian satellite Youthsat $(92 \mathrm{~kg})$.

- Class 1-“Nano": satellites with mass in the range $1-10 \mathrm{~kg}$ where cubesats (from $1 \mathrm{U}$ to $12 \mathrm{U}$, and mass below $10 \mathrm{~kg}$ ) constitute a subclass. However, the class also considers nanosats of non-standard shapes. All nanosats are classified as smallsats in terms of size.

- Class 0- "Pico": a class for small satellites in the mass range $0.1-1 \mathrm{~kg}$.

- Class-1- "Femto": a class for very small satellites in the mass range $0.01-0.1 \mathrm{~kg}$.

- Class-2-“Gram": a class for orbital particles with mass $<0.01 \mathrm{~kg}$ (10 grams) added for completeness. A class below femtosats should encompass possible technological advances in the opposite mass scale of large systems. However, gramsats already have past examples as the West Ford project [28]. The operational status of the particle in orbit defines whether such nanometric particles should be called gramsats or simply hazardous space debris.

Although the classification proposal is detailed for most of the operational spacecraft in orbit, its mass extremes reserve special classes for potential technological breakthroughs and/or future trends, for both the extremely small (gramsats) and much larger devices (megasats). Examples of such system are spacecraft-on-a-chip ${ }^{2}$ and very huge space stations or factories ${ }^{3}$, respectively. ${ }^{2}$ https://spectrum.ieee.org/aerospace/satellites/exploring-space-with-chipsized-satellites (Access: October 2019).

${ }^{3}$ https://www.universetoday.com/141523/gateway-foundation-shows-off-their-plans-for-an-enormo us-rotating-space-station/,

https://www.popularmechanics.com/space/satellites/a27886809/future-of-iss-space-station/ (Access: October 2019). 
Moreover, the proposed scheme can serve to better categorize launch vehicles in terms of the typical mass payloads they carry into space. In the presented proposal, size is used as an additional descriptor for the class, implying that additional classes may be necessary for large mass systems (e.g., above decasats).

\section{Conclusions}

The present work proposes a unified taxonomy for satellites based on mass and size with due consideration of past classifications. Our proposal observes the current trends arising from the intense technological progress of space systems, allowing us to define 10 classes of satellites subdivided into several types in accordance with mass ranges and size, from thousands of tons to less than 10 grams.

In particular, recent advances in circuit miniaturization have expanded the need for special classes for small systems. The trend recovers the initial attempts in the heydays of the space exploration when the first satellites were put into orbit as concept demonstrators. The microelectronic revolution has allowed the design of multifunctional satellites as small as a microchip, setting new size standards for the space industry like picosats and femtosats.

On the other side of the mass scale, the study has indicated the need for creating subcategories for larger masses, a territory little explored at the beginning of satellite classification. Such heavy system categories were predicted here, but were not further subdivided as will be necessary for future interstellar [29] and interplanetary exploration missions. Certainly, the proposal can accommodate large spacecraft and its potential categorization in accordance with the observed technological development. Our scheme thus proposes new classes for future space applications but also establishes a systematic direction for future use as an intermediary taxonomy to be improved. We emphasize that such general taxonomy should not be oriented by any particular objectives tied to space agencies, companies or other government organizations, but developed in accordance with technological progress only. An example of a trend has been seen already with the volume quantization introduced in Cubesats as important technological and cost reduction drives for nanosats. Since the standard is well accepted, size further categorizes any satellite with a mass larger than $10 \mathrm{~kg}$ as a minisat even though its assembly conforms to a $12 \mathrm{U}$ structure. Cubesats as a subclass of nanosats should have masses smaller than $10 \mathrm{~kg}$ compliant with the U-class block structure in agreement with the practice registered in the literature.

Finally, we further emphasize our belief that the future of satellite classification schemes still has to consider the power necessary to insert a payload into orbit, which can happen either through multiple insertions on a single launch or through dedicated launches. Such consideration should regard the trends in both current and future lift powers of launch services. The references presented in Table 17 and Table 18 are only an indication of such a continuous trend. In ad- 
dition, in future studies, a refinement of the scheme proposed here could be implemented by making reference to the spacecraft density-defined as the ratio of the dry mass to its minimum volume-which would allow for new attributes or subclasses. Large spacecraft in general, such as space stations, are mostly "empty" structures (hence, low-density devices), while smallsats are highly packaged as a result of the optimum packing attained during their assembly, therefore, an explicit dependency on density seems appropriate.

\section{Acknowledgements}

Authors would like to thank Simonny V. Soares (AEB) for revising the manuscript.

\section{Conflicts of Interest}

The authors declare no conflicts of interest regarding the publication of this paper.

\section{References}

[1] Kramer, H.J. and Cracknell, A.P. (2008) An Overview of Small Satellites in Remote Sensing. International Journal of Remote Sensing, 29, 4285-4337.

https://doi.org/10.1080/01431160801914952

[2] Noël, S., Bovensmann, H., Burrows, J.P., Frerick, J., Van Chance, K., Goede, A.P. and Muller, C. (1998) SCIAMACHY Instrument on ENVISAT-1. Sensors, Systems, and Next-Generation Satellites II, International Society for Optics and Photonics, 3498, 94-105. https://doi.org/10.1117/12.333621

[3] Volynskaya, O.A. and Kasyanov, R.A. (2016) Lauching Numerous Small Satellites-A Flourishing Business? The Case of the Russian Federation. In: Marboe, I., Ed., Small Satellites: Regulatory Challenges and Changes, Brill-Njihoff, Leiden. https://doi.org/10.1163/9789004312234_007

[4] Nag, S., LeMoigne, J. and De Weck, O. (2014) Cost and Risk Analysis of Small Satellite Constellations for Earth Observation. 2014 IEEE Aerospace Conference, Big-Sky, MT, 1-8 March 2014, 1-16. https://doi.org/10.1109/AERO.2014.6836396

[5] Simpson, G.G. (1961) Principles of Animal Taxonomy. Columbia University Press, New York. https://doi.org/10.7312/simp92414

[6] Tholen, D.J. and Barucci, M.A. (1989) Asteroid Taxonomy. Proceedings of the Conference Asteroids II, Tucson, AZ, 298-315.

[7] Brownlee, D.E., Olszewski, E. and Wheelock, M. (1982) A Working Taxonomy for Micrometeorites. Lunar and Planetary Science Conference, 13, 71-72.

[8] Levison, H.F. (1996) Comet Taxonomy. Completing the Inventory of the Solar System, 107, 173-191.

[9] Winsor, M.P. (2009) Taxonomy Was the Foundation of Darwin's Evolution. Taxon, 58, 43-49. https://doi.org/10.1002/tax.581007

[10] Shenhar, A.J. and Dvir, D. (1996) Toward a Typological Theory of Project Management. Research Policy, 25, 607-632. https://doi.org/10.1016/0048-7333(95)00877-2

[11] Shenhar, A.J. and Bonen, Z. (1997) The New Taxonomy of Systems: Toward an Adaptive Systems Engineering Framework. IEEE Transactions on Systems, Man, 
and Cybernetics-Part A: Systems and Humans, 27, 137-145. https://doi.org/10.1109/3468.554678

[12] Sweeting, M.N. (1991) Why Satellites Are Scaling Down. Space Technology International, 55-59.

[13] Botelho, A.S.R.C. and Xavier Jr., A.L. (2019) Em Direção a uma Taxonomia Unificada para Satélites com Base em Massa e Tamanho. Proceedings of the II Congresso Aeroespacial Brasileiro, UFSM, Santa Maria, RS, Brazil.

[14] Konecny, G. (2004) Small Satellites-A Tool for Earth Observation? Proceedings of 20 th ISPRS Congress, Commission, 4, 580-582.

[15] Li, X.Y., Guang, Y., Zhang, J., Xiao, Y. and Guo, J. (2008) Small Satellite Remote Sensing and Applications-History, Current and Future. International Journal of Remote Sensing, 29, 4339-4372. https://doi.org/10.1080/01431160801914945

[16] Schrogl, K.U. (1998) Basic Space Science at UNISPACE III 1999. United Nations Programme on Space Applications, 9, 141.

[17] NASA (2015) What Are SmallSats and CubeSats? https://www.nasa.gov/content/what-are-smallsats-and-cubesats

[18] Wekerle, T., Pessoa Filho, J.B., Costa, L.E.V.L. and da Trabasso, L.G. (2017) Status and Trends of Smallsats and Their Launch Vehicles-An Up-to-Date Review. Journal of Aerospace Technology and Management, 9, 269-286. https://doi.org/10.5028/jatm.v9i3.853

[19] ITU (2014) Characteristics, Definitions and Spectrum Requirements of Nanosatellites and Picosatellites, as well as Systems Composed of Such Satellites. Report ITU-R SA.

https://www.itu.int/dms_pub/itu-r/opb/rep/R-REP-SA.2312-2014-PDF-E.pdf

[20] FAA (2015) 2015 Commercial Space Transportation Forecasts. FAA Commercial Space Transportation (AST) and the Commercial Space Transportation Advisory Committee (COMSTAC).

https://brycetech.com/downloads/Commercial_Space_Transportation_Forecasts_2 015.pdf

[21] FAA (2016) The Annual Compendium of Commercial Space Transportation: 2016. FAA Commercial Space Transportation (AST).

https://www.faa.gov/about/office_org/headquarters_offices/ast/media/2016_Compe ndium.pdf

[22] FAA (2017) The Annual Compendium of Commercial Space Transportation: 2017. FAA Commercial Space Transportation (AST).

https://www.faa.gov/about/office_org/headquarters_offices/ast/media/2017_AST_C ompendium.pdf

[23] Federal Aviation Administration (FAA) (2018) The Annual Compendium of Commercial Space Transportation: 2018. FAA Commercial Space Transportation (AST).

https://www.faa.gov/about/office_org/headquarters_offices/ast/media/2018_AST_C ompendium.pdf

[24] Nason, I., Puig-Suari, J. and Twiggs, R. (2002) Development of a Family of Picosatellite Deployers Based on the CubeSat Standard. IEEE Aerospace Conference Proceedings, Big Sky, MT, 9-16 March 2002, 1.

[25] Swartwout, M. (2013) The First One Hundred Cubesats: A Statistical Look. Journal of Small Satellites, 2, 213-233.

[26] Weinzierl, M. (2018) Space, the Final Economic Frontier. Journal of Economic 
Perspectives, 32, 173-192. https://doi.org/10.1257/jep.32.2.173

[27] NASA (2010) DRAFT Launch Propulsion Systems Roadmap-Technology Area 01. https://www.nasa.gov/pdf/500393main_TA01-LaunchPropulsion-DRAFT-Nov2010 -A.pdf

[28] Lovell, A.C.B., Blackwell, M.R. and Wilson, R. (1962) West Ford Project, Interference to Astronomy from Belts of Orbiting Dipoles (Needles). Quarterly Journal of the Royal Astronomical Society, 3, 100-108.

[29] Long, K.F. (2011) Project Icarus: The First Unmanned Interstellar Mission, Robotic Expansion \& Technological Growth. Journal of the British Interplanetary Society, 64, 107-115. 